\title{
LETRAMENTO CRÍTICO ENTRE 2007 E 2008: UMA PESQUISA BIBLIOGRÁFICA VIA BANCO DE TESES DA CAPES
}

\author{
Juliane D`ALMAS, UEL \\ Vivian Uno LUNARDI, UEL
}

\begin{abstract}
Resumo: Este trabalho é uma continuação da pesquisa bibliográfica feita por REIS (2008) e visa a analisar trabalhos de Mestrado e Doutorado sobre letramento crítico registradas pelo banco de teses da CAPES, por meio da leitura de seus resumos. A partir disso, verifica em que áreas do conhecimento o conceito de letramento crítico está sendo aplicado e dá ênfase à análise do desenvolvimento de estudos sobre letramento crítico no campo do ensino de língua estrangeira, em especial da língua inglesa.
\end{abstract}

Palavras-chave: Letramento crítico; Língua estrangeira; Língua inglesa.

Abstract: This article is a sequence of the bibliographic research made by REIS (2008) and seeks to analyze Master's and Doctorate Degrees' papers about critical literacy published by the CAPES' thesis database, through the reading of its abstracts. From this, we verify in each areas of knowledge the concept of critical literacy is being applied and emphasizes the analysis of the development of the critical literacy studies in the filed of foreign language, in special of English.

Keywords: Critical Literacy; Foreign Language, English.

\section{INTRODUÇÃO}

Esta pesquisa bibliográfica é uma continuação da pesquisa feita por REIS (2008), que examinou pesquisas em letramento crítico publicadas de 1987 (ano 1 do banco de teses da CAPES) até 2006. Tal pesquisa investigou quantos estudos foram publicados, a que áreas do conhecimento pertenciam, em que regiões foram produzidas, que metodologia e referencial teórico adotaram. A pesquisa focalizou estudos relativos à língua estrangeira, em especial a língua inglesa, campo de atuação da autora e das autoras do presente trabalho.

A pesquisa bibliográfica é um instrumento importante, pois nos auxilia a obter uma visão mais abrangente do tema escolhido para um estudo. Tem por objetivo 
conhecer as diferentes contribuições científicas disponíveis sobre determinado tema. Ela dá suporte a todas as fases de qualquer tipo de pesquisa, uma vez que auxilia na definição do problema, na determinação dos objetivos, na construção de hipóteses, na fundamentação da justificativa da escolha do tema e na elaboração do relatório final. A pesquisa bilbiográfica permite colocar o pesquisador em contato direto com fontes de informação que retratam o assunto. Nas palavras de Barros e Lehfeld (1986, p. 91), "através deste tipo de pesquisa é que o investigador consegue melhores condições para formular e determinar o seu problema de pesquisa". Portanto, o pesquisador terá um aprofundamento maior sobre o tema para descobrir possíveis incoerências ou contradições, analisando-as cuidadosamente.

\section{O DESENVOLVIMENTO DE PEQUISAS NO CAMPO DO LETRAMENTO CRÍTICO EM LÍNGUA INGLESA}

Como mencionamos anteriormente, este estudo focaliza, prioritariamente, trabalhos realizados em torno do letramento crítico em língua inglesa. De acordo com a pesquisa inicial feita por REIS (2008), 14\% dos trabalhos publicados na área de Letras e Educação entre os anos de 1987 e 2006, são em língua inglesa e 86\% em língua materna. A maior parte desses $14 \%$ são pesquisas qualitativas de cunho etnográfico e relatam o ensino dessa língua estrangeira descrevendo as relações entre alunos e professores, professores em estágio de formação inicial e entre alunos que aprendem esse idioma.

Em outras palavras, a realização de atividades que incentivam o letramento crítico a partir do ensino de língua inglesa, de forma contextualizada, ainda é uma ação desencorajada, pouco praticada e, também, pouco pesquisada.

\section{LETRAMENTO CRÍTICO}

Consideramos relevante explicitar a diferença entre letramento e letramento crítico, e, além disso, conceituar o termo que este estudo investiga.

Primeiramente, vemos o termo letramento como a capacidade que um indivíduo possui de ler, escrever e se comunicar. Dessa forma, o sujeito se torna letrado, capaz de 
compreender o mundo a sua volta. Moita-Lopes (2005) destaca letramento como evento social situado, envolto em práticas sociais e discursivas. As práticas discursivas, segundo ele, seriam os modos de usar a linguagem e fazer sentido tanto na fala quanto na escrita. Essas práticas são associadas às visões particulares do mundo (crenças e valores) de grupos sociais e culturais particulares. Além disso, elas são inteiramente relacionadas com a identidade ou sentido de si-mesmo das pessoas que vivem essas práticas. Uma mudança de prática discursiva é uma mudança de identidade. Se tornar letrado, então, é estar em uma comunidade de prática na qual ocorrem trocas de práticas sociais e discursivas entre os participantes. A sala de aula, assim, pode ser vista como uma comunidade de prática, onde alunos interagem entre si e com o professor.

Quando as pessoas se engajam no discurso estão agindo no mundo em relação aos outros. Essas ações ocorrem quando as pessoas conversam, escrevem e quando fazem leituras de textos. Os significados que se constroem diante disso estão localizados em contextos específicos no momento de compreender o outro na co-construção do significado.

Dentro desta perspectiva de letramento apresentada por Moita-Lopes (2005), encontra-se o letramento crítico. Este faz parte de algo mais profundo, no qual o indivíduo deve ser capaz de enxergar e ler o mundo através de perspectivas mais humanizadoras, a fim de promover transformações e se tornar consciente das mudanças em vigência. Para Harrison (2004):

Critical literacy is different from literacy. Literacy, as most governments understand it, increases educational achievement levels, improves the jobmarket skills of the population and cuts down crime. Critical literacy does none of theses things: critical literacy challenges what schooling is attempt-workers, who are ready, when necessary, to challenge their bosses about working practices, about the ethics of production, about redundancies; and it makes those in prison able and more likely to complain about their conditions (p.155).

O letramento crítico visa à transformação social e à criação de novos discursos, observando as ideologias intrínsecas ao texto. Nesse campo, Freire (1993) é referência central. Ele considera o letramento como sendo um conhecimento adquirido que envolve a leitura do mundo e da palavra de forma crítica, para amenizar desigualdades sociais e promover mudanças sociais. O foco principal de sua pedagogia é transformar o contexto social dos marginalizados. Sua pedagogia (chamada de problematizadora por ele) é contra as ideologias dominantes. A forma que Freire (1993) encontra para isso é 
formar pessoas mais críticas, curiosas e indagadoras, para que sejam mais livres em relação aos seus próprios pensamentos.

Levando em conta a precedência de Freire no campo do letramento crítico, Cervetti, Pardales e Damico (2001) argumentam que o letramento crítico considera o significado de um texto como um processo de construção. Essa construção do significado se dá a partir do contexto histórico-social em que o texto está inserido, bem como das relações de poder. Então, o aluno não extrai, simplesmente, o significado do texto, pois o texto, em si, não possui significado; o aluno constrói significado a partir das condições de produção do texto. A leitura, assim, passa a ser um meio de transformação social. Ainda, de acordo com esses mesmos autores “[...] o letramento crítico envolve um entendimento da maneira como a ideologia e as práticas sociais moldam as representações das realidades nos textos" (no tópico 'Critical Literacy Approaches', sem página).

Endossando que as práticas de linguagem são uma forma de relação de poder, Fairclough $(1989,2001)$ argumenta que esta ocorre dentro do evento em que o texto está inserido. Dessa forma, denominam-se as categorias que ele defende serem essenciais para uma leitura voltada ao Letramento Crítico. Tais categorias seriam o que é dito ou feito no evento, as relações que os participantes mantêm e os papéis que eles representam.

Assim, analisar um texto, sob a perspectiva crítica, requer do leitor identificar qual é o evento discursivo presente no texto, quem são os participantes e qual posição eles ocupam e, então, verificar o tipo de linguagem que eles utilizam, para que seja possível manter relações sociais e estabelecer certa hierarquia entre eles. O leitor, então, observará o porquê de o texto ter sido escrito e qual a intenção do autor em estabelecer tais posições entre os participantes.

Pensamos que o professor, adotando essa perspectiva, poderá mostrar ao aluno o texto como uma prática social dentro de um evento discursivo cheio de ideologias e relações que não ocorrem de maneira aleatória. $\mathrm{O}$ aluno, consequentemente, conseguirá entender aquilo que está "por detrás das linhas"; visualizar o que não foi dito.

Além disso, de acordo com Mattos e Valério (2010) o letramento crítico vê a língua não só como uma ferramenta para a elaboração de significados, mas também enfoca a dimensão sócio-histórica desses significados e vê nela uma ferramenta de poder e de transformação social, como já argumentado por Freire (1993). Quanto ao desenvolvimento de competências, o letramento crítico tem como objetivo o 
desenvolvimento da consciência crítica mais do que outras competências específicas. Ainda para os mesmos autores, no letramento crítico o estudante aprende a língua materna ou estrangeira a fim de promover transformações a si mesmo e na sociedade, caso queira.

Por isso, consideramos o letramento crítico uma prática urgente para os dias de hoje, pois a linguagem está se tornando cada vez mais essencial no ato de determinar "a reprodução e sustentação das relações de poder que dominam e controlam a nossa sociedade" (HARRISON, 2004). Além do mais, pesquisas necessitam ser desenvolvidas nesse meio para que possamos compreender o panorama do ensino de letramento crítico.

\section{METODOLOGIA}

A presente pesquisa foi realizada na base de periódicos do portal da Coordenação de Aperfeiçoamento Pessoal de Nível Superior (CAPES).

Para encontrar o resumo dos trabalhos, o caminho percorrido foi o seguinte: acessamos o site do banco de teses da $\operatorname{CAPES}^{1}$ e, primeiramente, digitamos no campo "Assunto" o termo letramento crítico sem aspas, em seguida, selecionamos a opção Mestrado, no campo "Nível/Ano Base". Após selecionados os resumos referentes aos anos de 2007 e 2008, partimos para o nível de Doutorado, seguindo as mesmas etapas. A busca pelo mesmo termo digitado entre aspas não gerou resultados.

\section{RESULTADOS}

Os resultados encontrados serão apresentados, primeiramente, por um levantamento das áreas de conhecimento onde se originam essas pesquisas e das regiões onde foram desenvolvidas e publicadas. Em seguida, realizamos uma contagem do número de trabalhos, divididos pelos seus anos de publicação, as de 2007 e, posteriormente, as de 2008. Por fim, de acordo com o foco desta pesquisa, analisamos, principalmente, as dissertações e teses na área de Letras (incluindo Linguística e outras denominações), procurando por trabalhos que tenham o letramento crítico e o ensino de

\footnotetext{
${ }^{1}$ http://servicos.capes.gov.br/capesdw/Teses.do
} 
língua inglesa como tema. Por isso, detectamos os estudos desenvolvidos a partir do ensino de língua materna e a partir do idioma anteriormente mencionado.

\section{Áreas do Conhecimento}

As áreas do conhecimento das quais derivam esses estudos são diversas. Expressivo número de dissertações de Mestrado se concentra na grande área de Letras, na qual encontramos algumas subdivisões - Linguística, Linguística Aplicada, Língua Portuguesa, Letras Estrangeiras Modernas, Teoria e análise linguística - e até mesmo a nomenclatura Linguística, Letras e Artes, a qual consideramos semelhante à área de conhecimento anterior, mas que, de certa maneira abrange todas as divisões acima. Porém, a maior parte dessas pesquisas está relacionada à grande área de Educação, que também possui uma ramificação: Ensino - aprendizagem - tópicos específicos em Educação. Também encontramos um trabalho da área de Fonoaudiologia e outros da Psicologia e Comunicação, que aplicaram o termo letramento crítico em esferas que não se articulam com o ensino de leitura e/ou línguas.

\section{Regiões Brasileiras}

As regiões brasileiras que respondem pelas publicações são: Sudeste (com 23 trabalhos originários de São Paulo, Rio de Janeiro e Minas Gerais), Sul (com 12 estudos provenientes do Paraná, Santa Catarina e Rio Grande do Sul), Centro-Oeste (com 8 pesquisas oriundas do Distrito Federal e Mato Grosso) e por fim, o Nordeste (com 3 publicações derivadas de Alagoas e Ceará. Não foi encontrado nenhum registro de trabalhos realizados na região Norte do país.

\section{- 2007}

No ano de 2007 foram encontradas dez dissertações de Mestrado e seis teses de Doutorado, a que nos referimos a seguir.

\section{Mestrado}

Na área de Língua Portuguesa, encontra-se a dissertação de VAZ, que aborda o letramento a partir das vozes dos leitores na construção do gênero textual "box de correção". Portanto, um trabalho em língua materna. 
Os estudos de MARTINS e SOUZA se encaixam na área da Linguística Aplicada. Porém, ambos tratam do letramento em seu âmbito digital, relacionado ao uso de novas tecnologias e da internet. O primeiro relata as interações ocorridas em um ambiente virtual intitulado "Como Ler Um Texto Em Inglês", oferecido para alunos do Ensino Médio. O segundo investiga um curso para o letramento digital de professores de inglês. Sendo assim, ambas as pesquisas focalizavam a língua inglesa.

As pesquisas inseridas no âmbito da Educação trazem diversas aplicações para o conceito de letramento crítico. LAMBACH, por exemplo, aplica o letramento crítico em um trabalho sobre a atuação dos professores de química, que lecionam junto ao programa de Educação de Jovens e Adultos (doravante EJA), procurando caracterizar o estilo de pensamento desses docentes. Outra pesquisa que envolve a prática pedagógica é o de PEREIRA, que resulta de um estudo de caso sobre alunos de uma turma de progressão, procurando compreender a prática dos professores atuantes nesse ramo. GOMES também investiga o uso das novas tecnologias, aliando-as à formação de professores de alunos multirrepetentes por dificuldade da leitura e escrita. Nessa área, encontramos também o trabalho de KURZAWA, que discorre sobre a concepção de currículo que professores atuantes no EJA possuíam. Percebemos que nenhum dos estudos na área de educação estabelece qualquer relação com o ensino de línguas, mas aplicam o termo letramento crítico a outras propostas de pesquisa.

$\mathrm{Na}$ área de Letras encontramos apenas a dissertação de MARTINEZ, estudo etnográfico sobre concepções de linguagem e educação profissional de professores de língua inglesa no qual a autora relaciona conceitos teóricos sobre linguagem, conhecimento, educação, letramento crítico, ensino de línguas estrangeiras e educação de professores. Estes foram problematizados em relação às implicações que podem gerar na formação inicial de professores de línguas estrangeiras e no ensino/aprendizagem de línguas estrangeiras para cidadania.

Encontramos também uma pesquisa na área de Fonoaudiologia e outra na Psicologia. Aquela, escrita por ZORZI, trata das dificuldades de aprendizagem sob a perspectiva da escuta fonoaudióloga, relatando uma ponte com os profissionais da educação, a fim de criar possibilidades de intervenção. Esta, de autoria de GONDIM, versa sobre as implicações de ideais de felicidade em jovens usuários de comunidades virtuais, procurando investigar também o discurso usado por eles.

\section{Doutorado}


As seis teses de doutorado estão em sua maior parte concentradas na grande área de Letras e tratam do termo letramento em geral, sem referências ao letramento crítico.

$\mathrm{Na}$ área de Linguística Aplicada, encontram-se os estudos de FISCHER e, coincidentemente, FISCHER. O primeiro foca no desenvolvimento de práticas de letramento na esfera acadêmica em disciplinas de língua materna. $\mathrm{O}$ segundo aborda o letramento digital via internet na construção do conhecimento tecnológico e pedagógico do professor de inglês.

Outra tese que discorre sobre o letramento digital é de BALBONI, inserida na área de comunicação, que apresenta uma visão geral da importância das Tecnologias da Informação e da Comunicação (TICs) para a participação do cidadão na "sociedade da informação", apontando também para a necessidade do letramento. Ainda com a mesma preocupação, porém introduzido na área de Linguística, Letras e Artes, encontramos o trabalho de BUZATO, que analisa criticamente o contraste entre as diferentes visões da relação entre sociedade, cultura e tecnologia, que fundamentam os discursos acadêmicos, políticos e do senso comum em torno da inclusão digital na atualidade.

A pesquisa de SANTOS advoga o uso de gêneros para a constituição da base para o ensino de letramentos e está incluída na área de linguística.

Por fim, na área de conhecimento intitulada Letras Estrangeiras Modernas está a tese de THIAGO, que investiga criticamente o texto multimodal de autoria indígena.

\section{- 2008}

Em 2008, a quantidade de trabalhos encontrados através da digitação do termo letramento crítico gerou um número maior, comparado a 2007. Foram, no total, 25 dissertações de Mestrado e cinco teses.

\section{Mestrado}

Grande parte das dissertações se insere na área de Educação, somando oito publicações. São elas: LORO, que investiga algumas das representações que um grupo de professoras tem sobre o brincar e conclui que esta prática auxilia no letramento. MENDES investiga as concepções de leitura adotadas por professores em sala de aula, suas atividades e se estas contribuem para a formação do aluno-leitor. O trabalho de LEAL é uma análise de currículo e pretende discutir as concepções de letramentonumeramento que perpassam o texto do Referencial Curricular Nacional de Educação Infantil (RCNEI). Outra dissertação sobre análise curricular é a de RIBEIRO, que 
analisa o currículo proposto para o Ciclo Inicial de Alfabetização da Secretaria Estadual de Minas Gerais e identifica as práticas pedagógicas prescritas por esse currículo, para que haja sucesso no processo de Alfabetização apresentando conceitos de letramento. HUMMELGEN apresenta uma investigação crítico-reflexiva acerca do papel da oralidade e de gêneros orais em materiais didáticos, de Ensino Fundamental. A pesquisa de caráter documental, de BETHONICO, analisa o modo com que os livros didáticos de língua portuguesa das séries iniciais $\left(1^{\mathrm{a}}\right.$ a $\left.4^{\mathrm{a}}\right)$ atuam na construção de cidadãos conscientes e críticos quanto ao consumo. O estudo de SILVA investiga as práticas de leitura presentes em uma sala da EJA e questiona se elas favorecem o letramento dos alunos. GUITARRARA apresenta uma pesquisa sobre a influência que o computador pode ter na aprendizagem de leitura e escrita, tornando-se um instrumento de mediação. As dissertações citadas acima, quando tratam de trabalho em sala de aula, foram todas realizadas na disciplina de língua portuguesa.

Encontramos quatro trabalhos na área de Letras. O de LOPEZ, por exemplo, é o único que aborda a língua estrangeira e disserta sobre como os alunos de formação inicial em língua inglesa leem um texto narrativo. O estudo de GARCIA investiga como ocorre a relação de professores e alunos com a TV em sala de aula e como esses professores são preparados para trabalhar com a TV como objeto de leitura. Em seguida, encontramos a pesquisa de REIS, que se trata de um processo de compreensão de como professores da rede pública estão aplicando a Lei Federal n. ${ }^{\circ}$ 10.639/2003, que discorre sobre as relações étnico-raciais no contexto escolar, tendo como uma de suas fundamentações teórico-metodológicas, o letramento crítico. Por fim, nessa área também se insere a dissertação de SOARES, que realizou um rastreamento das orientações e dos modelos de letramento literário em materiais pedagógicos.

$\mathrm{Na}$ grande área denominada Letras, Linguística e Artes foram encontrados 3 resumos, sendo eles o de OLIVEIRA, QUINHONHE e SANTOS. A primeira apresenta as concepções de leitura que permeiam os livros didáticos de língua espanhola dos alunos do Ensino Médio. A segunda discute a influência das práticas de letramento escolar no processo de formação do leitor proficiente. A última apresenta um estudo de uma narrativa ${ }^{2}$, fazendo uma análise de sua linguagem e poesia, com subsídios da teoria crítica, a qual não é sinônimo de letramento crítico.

\footnotetext{
${ }^{2}$ Cf. Vidas Secas de Graciliano Ramos.
} 
A busca também nos ofereceu quatro estudos da área de Linguística Aplicada. CASTRO avalia o impacto da disciplina pedagógica como ferramenta para a formação específica, no caso, leitura e produção textual do futuro professor de língua materna em formação. A pesquisa de CORADIM investiga as interpretações de duas professoras do Ensino Médio quanto às Orientações Curriculares para o Ensino Médio (doravante OCEM). O trabalho de BOAVENTURA relata como as práticas de letramento televisivo crítico favorecem conversas sobre as relações raciais e redefinem a identidade de raça de alunos do Ensino Fundamental. Tratando também sobre identidades encontra-se a pesquisa de VINISKOFSKE, que aborda o processo de construção de identidades profissionais que ocorre durante entrevistas realizadas por uma professora com seus alunos-executivos em preparação para um determinado teste.

$\mathrm{Na}$ área de linguística, apenas três dissertações foram encontradas. O estudo de MOURA investiga como o significado de um texto em português pode ser negociado em LIBRAS, tendo como uma das fundamentações teóricas o letramento crítico. JÚNIOR também pesquisa o contexto da inclusão que aborda os discursos, as práticas de letramento (práticas de leitura e escrita) e as identidades docentes em relação à inclusão de alunas e alunos surdos no Ensino Regular. CARVALHO objetiva desenvolver em sua dissertação uma metodologia de leiturização que abarque a leitura explícita, a leitura inferencial e a leitura crítica dos alunos da EJA.

Para finalizar, encontramos três outras áreas do conhecimento, cada uma com um exemplar de pesquisa: (1) teoria e análise linguística, (2) ensino-aprendizagem - tópicos específicos de educação - e (3) Letras Estrangeiras Modernas. Na primeira está inserido o estudo de BARROS, que foca nas situações de produção/circulação/recepção mais imediatas dos textos, como também as coerções sócio-histórico-ideológicas que perpassam as mais variadas práticas de linguagem consolidadas em nossa sociedade. $\mathrm{Na}$ segunda, encontramos o trabalho de AUGÉ, que investiga a incitação pelo gosto da escrita e da leitura através da construção de um jornal por alunos do Ensino Fundamental na aula de língua materna. A dissertação de MOTTA, por fim, pertence à última categoria e focaliza práticas e eventos de letramento observados no ensino de leitura em inglês de duas escolas do Ensino Médio.

\section{Doutorado}

Encontramos cinco teses de doutorado datadas de 2008. 
Na área de Linguística Aplicada, a tese de TINÔCO, que estuda projetos de letramento entendidos como um modelo didático articulador dos estudos do letramento, da pedagogia de projetos e do aporte metodológico da pedagogia crítica. A tese investiga princípios de ressignificação do ensino de escrita através de diversas atividades desenvolvidas pelos alunos de Letras da universidade em que a pesquisa se insere.

A pesquisa de SILVA, concentrada na área de Linguística, trata da construção das identidades de gênero, especialmente a das mulheres, na relação com o letramento no contexto escolar.

Em Letras Estrangeiras Modernas, encontra-se o trabalho de IOKAKI, que enfoca os letramentos como questão crucial à aprendizagem e investiga como estudantes universitários, usuários da internet, constroem sentidos a partir de seus contextos sócio-culturais, em relação às diferentes formas de prática social e respectivas epistemologias, tendo como base o letramento crítico.

NINCAO apresenta uma tese que tem como objetivo refletir sobre o processo de produção de textos em língua indígena por parte de professores Terena. O estudo se concentra na área de Linguística, Letras e Artes.

A última tese encontrada está na área de língua portuguesa e é de autoria de CONCEIÇÃO, com objetivos estudar os modos de representação do papel do professor de língua portuguesa construídos por acadêmicos do curso de Letras e fornecer elementos para propostas de intervenção na formação de professores da referida graduação.

\section{CONTRIBUIÇÕES DAS PESQUISAS PARA O LETRAMENTO CRÍTICO EM LÍNGUA INGLESA}

Através da leitura dos resumos de dissertações e teses publicados no período 2007 a 2008, percebemos que predominam estudos voltados às áreas de Educação e Letras, em sua maioria em língua portuguesa.

Encontramos, no total, nove trabalhos em língua estrangeira, sendo eles dois em língua indígena, um em língua espanhola, um que não especifica, no seu resumo ${ }^{3}$, a língua pesquisada e o restante (cinco) em língua inglesa.

\footnotetext{
${ }^{3} \mathrm{O}$ trabalho por completo não estava disponibilizado na internet, por isso, não conseguimos investigar a fundo a que língua estrangeira este se referia.
} 
Concluímos que os trabalhos mais relevantes para a área são o de CORADIM (2008), MOTTA (2008) e MARTINEZ (2007), todas dissertações de Mestrado. Há ainda os estudos de SOUZA (2007), este defendido para obtenção de título de mestre, e a tese de FISCHER (2007). Porém, ambos tratam do letramento crítico no contexto de letramento digital influenciando as práticas e a formação do futuro professor de língua inglesa. Já as pesquisas citadas anteriormente abordam especificamente o ensinoaprendizagem do letramento crítico em diversos contextos. CORADIM analisa as cognições de duas professoras de Ensino Médio sobre as concepções de letramento crítico trazidos pelas OCEM. MOTTA investiga o ensino de leitura em língua inglesa em duas escolas do Ensino Médio através da análise das atividades aplicadas, entrevistas com as docentes e depoimentos de alunos, identificando, dessa forma, concepções de linguagem, leitura e educação presentes naqueles ambientes. No mesmo contexto, registra-se a pesquisa de MARTINEZ, sobre concepções de linguagem e educação profissional de professores de língua inglesa, relacionando as concepções de linguagem, letramento crítico, educação, ensino de línguas estrangeiras e as OCEM.

\section{CONSIDERAÇÕES FINAIS}

De acordo com as pesquisas feitas para este artigo, observamos um crescimento no número de pesquisas voltadas ao letramento crítico na área da Educação em língua portuguesa. No entanto, o número de pesquisas sobre letramento crítico, voltadas para a língua inglesa, continua carente de estudos. Isso nos leva a supor que essa carência resulta de mudanças recentes no ensino em língua portuguesa e em língua inglesa. Tais mudanças acabam fazendo com que o foco nas pesquisas seja a língua materna, já que esta é usada cotidianamente por maior número de pessoas no Brasil. No entanto, sabemos da expansão que a língua inglesa tem hoje, através da importância, cada vez maior, de se ter uma língua por meio da qual todos consigam se comunicar. Reflexo disso são pesquisas que estabelecem discussões acerca do inglês como sendo língua franca, que removem o prestígio da língua inglesa americana e da britânica.

Neste artigo, evidenciamos a falta de pesquisas na área do letramento crítico na língua inglesa. Diante da importância da língua inglesa na atualidade global, sugerimos que pesquisas sejam feitas para suprir tal lacuna de conhecimento.

\section{REFERÊNCIAS}


AUGÉ, M. E. V. O Jornal Escolar: Escrita e Pensamento. 2008. 136 p. Dissertação (Mestrado em Educação) - Universidade Federal de Pelotas, Pelotas.

BALBONI, M. R. Por detrás da inclusão digital: Uma reflexão sobre o consumo e a produção de informação em centros públicos de acesso à Internet no Brasil. 2007. 242 p. Tese (Doutorado em Ciências da Comunicação) - Universidade de São Paulo. São Paulo.

BARROS, A. J. P. de; LEHFELD, N. A. de S.. Fundamentos de metodologia: um guia para a iniciação científica. São Paulo: MCGraw-Hill, 1986.

BARROS, E. M. D. de. A apropriação do gênero crítica de cinema como um processo de letramento. 2008. 250 p. Dissertação (Mestrado em Estudos da Linguagem) - Universidade Estadual de Londrina, Londrina.

BETHONICO, J. M. Letramento em marketing: o livro didático de lingua portuguesa de $1^{\mathrm{a}}$ a $4^{\mathrm{a}}$ série na formação de comunicadores criticos. $2008.276 \mathrm{P}$. Dissertação (Mestrado em Educação) - Universidade Federal de Minas Gerais, Belo Horizonte.

BOAVENTURA, L. M. V. Letramento televisivo na escola: os discursos sobre raça em xeque. 2008. 187 p. Dissertação (Mestrado em Linguística Aplicada) Universidade Federal do Rio de Janeiro, Rio de Janeiro.

BUZATO, M. E. K. Entre a Fronteira e a Periferia: linguagem e letramento na inclusão digital. 2007. 277 p. Tese (Doutorado em Linguística Aplicada) - Universidade Estadual de Campinas, Campinas.

CARVAlHO, R. D. de. A Leiturização Como Prática de Letramento na Educação de Jovens e Adultos. 2008. 150 p. Dissertação (Mestrado em Linguística) Universidade de Brasília, Brasília.

CASTRO, H. M. C. de. Disciplina pedagógica como ferramenta para a formação específica (leitura e produção textual) do professor de língua materna. 2008. 99 p. Dissertação (Mestrado em Linguística Aplicada) - Universidade de Taubaté, Taubaté.

CERVETTI, G., PARDALES, M.J., DAMICO, J.S. (2001, April). A tale of differences: Comparing the traditions, perspectives, and educational goals of critical reading and critical literacy. Disponível em: $<$ http://www.readingonline.org/articles/art_index.asp?HREF=/articles/cervetti/index.ht $\mathrm{ml}>$. Acessado em junho/2010.

CONCEIÇÃO. R. I. S. O professor de língua portuguesa na visão de formandos de letras. 2008. 299 p. Tese (Doutorado em Filologia e Língua Portuguesa) - Universidade de São Paulo, São Paulo.

CORADIM, J. N. Leitura crítica e letramento crítico: idealizações, desejos ou (im)possibilidades. 2008. 122 p. Dissertação (Mestrado em Estudos da Linguagem) Universidade Estadual de Londrina, Londrina. 
CRAWFORD, J.C. English as a lingua franca: Implications for the teacher education programs. In: $22^{\text {nd }}$ International Conference on English Teaching and Learning in the Republic of China, June 2005, National Taiwan Normal University, Taipei, Taiwan. 2005.

FAIRCLOUGH, N. Language and Power. 1989/2001. London: Longman.

FISCHER, A. A Construção de Letramento na Esfera Acadêmica. 2007. 340 p. Tese (Doutorado em Linguística Aplicada) - Universidade Federal de Santa Catarina, Florianópolis.

FISCHER, C. R. . Formação tecnológica e o professor de inglês: explorando níveis de letramento digital. 2007. 218 p. Tese (Doutorado em Linguística Aplicada) - Pontifícia Universidade Católica de São Paulo, São Paulo.

FREIRE, P. Pedagogia do oprimido. 1993. Paz e Terra.

GARCIA. L. A. R. A Televisão na Escola como Objeto ce Leitura: Uma Proposta de Letramento Midiático Televisivo. 2008. 153 p. Dissertação (Mestrado em Letras) Universidade Estadual de Maringá, Maringá.

GIMENEZ, T. . English in a new world language order. In: Loreni Machado; Vera Lúcia Lopes Cristovão; Viviane Bagio Furtoso. (Org.). Aspectos da linguagem: considerações teórico-práticas. Londrina: Universidade Estadual de Londrina, 2006, v. , p. 59-71.

GOMES, R. O de A. Aprendizagem e Ensino com software livre: pesquisa e intervenção na formação de professores. 2007. 164 p. Dissertação (Mestrado em Educação) - Universidade Estadual do Ceará, Fortaleza.

GONDIM, M. S. Felicidade no Ciberespaço: Um Estudo com Jovens Usuários de Comunidades Virtuais. 2007. 166 p. Dissertação (Mestrado em Psicologia) Universidade Federal do Ceará, Fortaleza.

GUITARRARA, S. H. da S. O computador na aprendizagem da leitura e da escrita: o processo de mediação. 2008. 103 p. Dissertação (Mestrado em Educação) - Centro Universitário Moura Lacerda, Ribeirão Preto.

HARRISON, C. - Developing critical literacy: text, discourse and the collaborative construction meaning. In: Understanding reading development. London: Sage. 2004.

HUMMELGEN, G. de F. P. A Oralidade e os Gêneros Orais em Livros Didáticos de Língua Portuguesa. 2008. 160 p. Dissertação (Mestrado em Educação) - Universidade São Francisco, Itatiba.

IOKAKI, N. H. Letramentos na sociedade digital: navegar é e não é preciso. 2008. 190 p. Tese (Doutorado em Estudos Linguísticos e Literários em Inglês) - Universidade de São Paulo, São Paulo. 
JÚNIOR, J. R. L. B. Os Discursos Docentes sobre Inclusão de Alunas e Alunos Surdos no Ensino Regular: Identidades e Letramentos. 2008. 151 p. Dissertação (Mestrado em Linguística) - Universidade de Brasília, Brasília.

KURZAWA, G. O Currículo na Educação de Jovens e Adultos: Investigando as Significações Sociais Elaboradas pelo Educador. 2007. 102 p. Dissertação (Mestrado em Educação) - Universidade Federal de Santa Maria, Santa Maria.

LAMBACH, M. Atuação e Formação dos Professores de Química na EJA: Características dos Estilos de Pensamento - um olhar a partir de Fleck. 2007. 178 p. Dissertação (Mestrado em Educação Científica e Tecnológica) - Universidade Federal de Santa Catarina, Florianópolis.

LEAL, F. R. de O. Letramento e Numeramento no Currículo Oficial para a Pequena Infância: problematizando concepções no Referencial Curricular de Educação Infantil. 2008. 89 p. Dissertação (Mestrado em Educação) - Universidade São Francisco, Bragança Paulista.

LOPEZ. G. T. C. Um Estudo de Caso. Leitura de Narrativa de Acadêmicos do Instituto de Línguas da Universidade Estadual de Maringá. 2008. 126 p. Dissertação (Mestrado em Letras) - Universidade Estadual de Maringá, Maringá.

LORO, A. P. FORMAÇÃO DE PROFESSORES E REPRESENTAÇÕES SOBRE O BRINCAR: Contribuições das idéias de Humberto Maturana. 2008. 112 p. Dissertação (Mestrado em Educação) - Universidade Federal de Santa Maria, Santa Maria.

MARTINEZ, J. Z. Uma Leitura sobre Concepções de Linguagem e Educação Profissional de Professores de Língua Inglesa. 2007. 162 p. Dissertação (Mestrado em Letras) - Universidade Federal do Paraná, Curitiba.

MARTINS, P. de S. . A aplicação de um ambiente virtual de aprendizagem no contexto do nível médio de ensino: a plataforma e-Proinfo em uso. 2007. 100 p. Dissertação (Mestrado em Linguística Aplicada) - Universidade federal do Rio de Janeiro, Rio de Janeiro.

MATTOS, A. M. A.; VALÉRIO, K. M. - Letramento crítico e ensino comunicativo: lacunas e interseções. In: RBLA. Belo Horizonte, v.10, n.1, 2010. p.135-158.

MENDES, C. C. M. Leitura: concepções e práticas de professores e alunos, em uma escola pública de Cuiabá-MT. 2008. 172 p. Dissertação (Mestrado em Educação) Universidade federal de Mato Grosso, Cuiabá.

MOITA-LOPES, L. P. A construção do gênero e do letramento na escola: como um tipo de conhecimento gera o outro. 2005. Investigações: Lingüística e Teoria Literária, Recife, v. 17, n. 2, p. 47-68.

MOTTA, T. F. Leitura em Inglês no Ensino Médio: uma análise da atividade de leitura na escola e sua relação com a comunicação mediada por novas tecnologias. 
2008. 173 p. Dissertação (Mestrado em Estudos Linguísticos e Literários em Inglês) Universidade de São Paulo, São Paulo.

MOURA, R. D. O Uso da Libras no Ensino de Leitura de Português como Segunda Língua para Surdos: Um Estudo de Caso em Uma Perspectiva Bilíngue. 2008. 102 p. Dissertação (Mestrado em Linguística Aplicada e Estudos da Linguagem) - Pontifícia Universidade Católica de São Paulo, São Paulo.

NINCAO, O. S. Kóho Yoko Hovôvo/O Tuiuiú e o Sapo: Biletramento, iden- tidade e política linguística na formação continuada de professores terena. 2008. 200 p. Tese (Doutorado em Linguística Aplicada) - Universidade Estadual de Campinas, Campinas.

OLIVEIRA, C. E. de. Concepções de leitura nos livros didáticos de língua espanhola: uma reflexão discursiva sobre a leitura em língua estrangeira. 2008. 88 p. Dissertação (Mestrado em Estudos da Linguagem) - Universidade Federal de Mato Grosso, Cuiabá.

PEREIRA, R. B. F. Cenas da sala de aula: práticas pedagógicas e perfis de alunos de uma turma de progressão de Campo Grande, RJ. 2007. 115 p. Dissertação (Mestrado em Educação) - Universidade Católica de Petrópolis, Petrópolis.

QUINHONE, E. O. M. Letramento escolar e formação do leitor crítico: um estudo sobre a rede municipal de Cuiabá. 2008. 220 p. Dissertação (Mestrado em Estudos da Linguagem) - Universidade Federal de Mato Grosso, Cuiabá.

REIS, R. C. da C. Diversidade étnico-racial: a Lei Federal n. $^{\circ}$ 10.639/2003 e abordagens possíveis em sua aplicação. 2008. 172 p. Dissertação (Mestrado em Letras) - Universidade Estadual do Oeste do Paraná, Cascavel.

REIS, S. Pesquisa em Letramento Crítico no Brasil: Um levantamento de dissertações e teses de 1987 a 2006. In: Andrade, O.G.; Durão, A.B.A.B.; Reis, S. Reflexões rumo sobre o Ensino das Línguas Estrangeiras. Londrina: Moriá, 2008.

RIBEIRO, V. R. O Currículo do Ciclo Inicial de Alfabetização de Minas Gerais: inovação ou continuidade? - Uma análise da proposta curricular do ciclo inicial de alfabetização da Rede Pública Estadual de Minas Gerais. 2008. 142 p. Dissertação (Mestrado em Educação) - Pontifícia Universidade Católica de Minas Gerais, Belo Horizonte.

SANTOS, E. C. da S. Gêneros e práticas de letramento no Ensino Fundamental. 2007. 258 p. Tese (Doutorado em Linguística) - Universidade de Brasília, Brasília.

SANTOS, F. J. dos. Linguagem, poesia e resistência em Vidas secas: na origem, o poder de nomear. 2008. 117 p. Dissertação (Mestrado em Letras e Linguística) Universidade Federal de Alagoas, Maceió.

SILVA. L. R. da. As identidades femininas: discurso e letramento no contexto escolar. 2008. 338 p. Tese (Doutorado em Linguística) - Universidade de Brasília, Brasília. 
SILVA, M. F. P. S. e. Práticas de leitura e letramento em uma sala de EJA em Rondonópolis-MT. 2008. 160 p. Dissertação (Mestrado em Educação) - Universidade Estadual de Mato Grosso, Cuiabá.

SOARES, S. R. Letramento Literário: Materiais Didáticos e o Ensino da Literatura. 2008. 129 p. Dissertação (Mestrado em Letras) - Universidade Estadual de Maringá, Maringá.

SOUZA, V. V. S. "LETRAMENTO DIGITAL CONTEXTUALIZADO: uma experiência na formAÇÃO continuada de professores". 2007. 244 p. Dissertação (Mestrado em Linguística) - Universidade Federal de Uberlândia, Uberlândia.

THIAGO, E. M. C. P de S. O texto multimodal de autoria indígena: narrativa, lugar e interculturalidade. 2007. 267 p. Tese (Doutorado em Estudos Linguísticos e Literários em Inglês) - Universidade de São Paulo, São Paulo.

TINÔCO, G. M. A. de M. Projetos de Letramento: Ação e Formação de professores de Língua Materna. 2008. 215 p. Tese (Doutorado em Linguística Aplicada) Universidade Estadual de Campinas, Campinas.

VAZ, C. A. Gênero do Discurso como Prática Social: as vozes dos leitores na construção do "box de correção. 2007. 89 p. Dissertação (Mestrado em Letras) Universidade Federal do Rio de Janeiro, Rio de Janeiro.

VINISKOFSKE, M. Falo o que 'nego' quer ouvir: identidades camaleônicas na nova ordem do trabalho. 2008. 188 p. Dissertação (Mestrado em Linguística Aplicada) Universidade Federal do Rio de Janeiro, Rio de Janeiro.

ZORZI, D. S. As dificuldades de aprendizagem sob a perspectiva da escuta fonoaudiológica e do olhar dos profissionais da Educação: construindo possibilidades de intervenção. 2007. 133 p. Dissertação (Mestrado em Fonoaudiologia) - Pontifícia Universidade Católica de São Paulo, São Paulo. 